Удк 676.16

\title{
ПОЛУЧЕНИЕ КАЛИЕВОЙ СОЛИ КАРБОКСИМЕТИЛИРОВАННОЙ ДРЕВЕСИНЫ СОСНЫ В УСЛОВИЯХ МИКРОВОЛНОВОГО ИЗЛУЧЕНИЯ
}

\author{
() В.И. Маркин ${ }^{*}$ М.Ю. Чепрасова, Н.Г. Базарнова, Е.О. Фролова \\ Алтайский государственный университет, пр. Ленина, 61, Барнаул, 656049 \\ (Россия), e-mail: markin@chem.asu.ru
}

Для интенсификации процесса карбоксиметилирования древесины сосны без предварительного разделения на отдельные компоненты предложено использовать микроволновое излучение. С целью получения карбоксиметилированной древесины сосны в виде калиевой соли проведена обработка древесины сосны гидроксидом калия и монохлоруксусной кислотой в среде пропанола-2. Изучены состав и свойства полученных продуктов. Из карбоксиметилированной древесины сосны выделена карбоксиметилированная целлюлоза. Установлено, что увеличение мощности микроволнового излучения (от 210 до 700 Вт) и продолжительности первой и второй стадий процесса карбоксиметилирования (20-30 сек) приводит к повышению содержания карбоксиметильных групп (18,3-25,6\%). Обнаружена аномально низкая растворимость калиевых солей карбоксиметилированной древесины сосны (10-18\%) по сравнению с натриевыми солями при сравнимом содержании карбоксиметильных групп. Проведено исследование вязкости водных растворов карбоксиметилированной древесины сосны и карбоксиметилированной целлюлозы, выделенной из нее. Показано, что образцы, полученные при мощности микроволнового излучения 210 Вт, обладают аномальными кривыми течения.

Ключевые слова: микроволновое излучение, карбоксиметилирование, калиевая соль, древесина, карбоксиметилцеллюлоза, кривые течения.

\section{введение}

Химическому модифицированию растительного сырья без предварительного разделения на отдельные компоненты с целью получения композиций, содержащих все основные модифицированные структурные компоненты, в последние годы уделяется большое внимание во многих странах мира [1-3].

Одним из перспективных направлений является получение карбоксиметиловых эфиров на основе растительного сырья. Применение разных способов карбоксиметилирования (суспензионный [4], твердофазный [5]), использование различных видов растительного сырья, регулирование условий процесса - все это позволяет получать продукты с самыми разнообразными свойствами [6].

Особый интерес представляет разработка методов карбоксиметилирования древесины с использованием микроволнового излучения, который приводит к равномерному нагреву древесины по всему объему. Установлено, что микроволновое излучение при карбоксиметилировании растительного сырья снижает продолжительность процесса (до 200 раз), по сравнению с традиционным нагревом [7]. Использование микроволнового излучения при химическом модифицировании растительного сырья является весьма перспективным направлением в химии древесины.

Цель настоящей работы - провести карбоксиметилирование древесины сосны монохлоруксусной

Маркин Вадим Иванович - доцент кафедры органической химии, кандидат химических наук, тел.: (3852) 36-95-37, e-mail: markin @ chemwood.asu.ru

Чепрасова Марина Юрьевна - ассистент кафедры органической химии, тел.: (3852) 36-95-37, e-mail: marinacheprasova@yandex.ru Базарнова Наталья Григорьевна - заведующая кафедрой органической химии, профессор, доктор химических наук, тел.: (3852) 36-95-37, e-mail: bazarnova@chemwood.asu.ru Фролова Евгения Олеговна - студентка кислотой в присутствии гидроксида калия в среде пропанола-2 под воздействием микроволнового излучения и изучить их свойства.

\section{Экспериментальная часть}

Характеристика исходного сырья. В работе использовали древесину сосны обыкновенной (Pinus silvestris) с фракцией опилок 0,315-0,630 мм и влажностью 5,5-6,0\%. Содержание основных структурных компонентов в растительном сырье определяли

\footnotetext{
* Автор, с которым следует вести переписку.
} 
по стандартным методикам: целлюлозу - по методике Кюршнера (азотно-спиртовым методом), лигнин с 72\%-ной серной кислотой в модификации Комарова [8]. В исходной древесине сосны содержание целлюлозы составило $44,8 \pm 0,4 \%$; лигнина $-29,9 \pm 0,9 \%$.

Карбоксиметилирование растительного сырья. Стадия І. Навеску опилок древесины сосны (5 г) помещали в фарфоровую ступку, прибавляли 4,1 г предварительно измельченного гидроксида калия и 50 мл пропанола-2; энергично растирали в ступке пестиком и количественно переносили в колбу Эрленмейера. Полученную смесь подвергали воздействию микроволнового излучения мощностью 210-700 Вт в течение 20-30 с при интенсивном перемешивании в оригинальной установке [6].

Стадия II. После обработки микроволновым излучением добавляли 6,9 г монохлоруксусной кислоты, тщательно перемешивали, до получения однородной массы и обрабатывали микроволновым излучением мощностью 210-700 Вт в течение 20-30 с.

Полученный продукт отмывали водным раствором этанола (70\%), добавляя для нейтрализации 90\%ную уксусную кислоту, до отрицательной реакции на щелочь по фенолфталеину и на хлорид ионы с раствором нитрата серебра, а затем сушили на воздухе.

Исследование продуктов карбоксиметилирования растительного сырья. Карбоксиметилированные продукты анализировали на содержание карбоксиметильных групп, вводимых при реакции, методом кондуктометрического титрования [9] с поправкой на ион калия. Растворимость полученных образцов определяли в соответствии с методикой, основанной на растворении продукта в воде и последующей фильтрации этого раствора через пористый стеклянный фильтр [9].

Карбоксиметилцеллюлозу (КМЦ) выделяли из карбоксиметилированной древесины 15\% надуксусной кислотой в соответствии с ранее разработанной методикой [10].

Степень полимеризации (СП) КМЦ, выделенной из карбоксиметилированной древесины, оценивали по изменению вязкости раствора в кадоксене в соответствии с методикой [11].

Изучение реологических свойств.

Исследование реологических свойств водных растворов калиевой соли карбоксиметилированной сосны и карбоксиметилированной целлюлозы, выделенной из нее проводили на ротационном вискозиметре НААКЕ VT550. Для этого в цилиндр измерительной системы NV (для измерения свойств низковязких растворов) помещали в 9 мл, предварительно приготовленного водного раствора калиевой соли карбоксиметилированной древесины сосны (0,1\% раствор), закрепляли в вискотесторе VT550, термостатировали при заданной температуре в течение 10 мин и проводили измерения под управлением программного обеспечения RheoWin 4.0.

\section{Обсуждение результатов}

В таблице представлено изменение содержания карбоксиметильных групп (КМГ), растворимость в воде калиевых солей карбоксиметилированной древесины сосны, а также характеристики выделенной из нее карбоксиметилцеллюлозы в виде калийной соли (К-КМЦ). Как следует из представленных данных, увеличение мощности микроволнового излучения (МВИ) и продолжительности стадий обработки гидроксидом калия и монохлоруксусной кислотой приводит к повышению содержания карбоксиметильных групп, что сравнимо с содержанием КМГ в продуктах карбоксиметилирования древесины в натриевой форме [7]. Однако следует отметить низкие значения растворимости в воде (несмотря на высокое содержание карбоксиметильных групп), что требует дальнейшего подробного изучения.

Из образцов карбоксиметилированной древесины сосны была выделена карбоксиметилцеллюлоза с помощью надуксусной кислоты и исследованы ее характеристики (выход, степень полимеризации, содержание карбоксиметильных групп, растворимость в воде). Из полученных данных следует, что с увеличением мощности и продолжительности МВИ снижается выход К-КМЦ и повышается содержание КМГ в продукте. Степень полимеризации К-КМЦ остается высокой практически для всех образцов.

Изучены реологические свойства водных растворов карбоксиметилированной древесины сосны и К-КМЦ, выделенной из нее (рис. 1, 2).

Характер кривых, отражающих изменение вязкости от градиента скорости вращения ротора, свидетельствует, что водный раствор карбоксиметилированной древесины сосны, полученной при мощности микроволнового излучения 210 Вт, имеет аномальный характер по сравнению с растворами продуктов, полученных при мощности микроволнового излучения 350-700 Вт. Аналогичную картину мы можем наблюдать при анализе кривых, отражающих изменение вязкости водных растворов К-КМЦ. Кривая течения К-КМЦ, выделенной из карбоксиметилированной древесины сосны, полученной под воздействием микроволнового излучения мощностью 210 Вт, также резко отличается от кривых для образцов, полученных при мощностях 350-700 Вт. 
Состав и свойства карбоксиметилированной древесины сосны (калиевая соль) в зависимости от условий реакции карбоксиметилирования под воздействием микроволнового излучения в среде пропанола-2

\begin{tabular}{|c|c|c|c|c|c|c|c|}
\hline \multirow{2}{*}{$\begin{array}{c}\text { Мощность } \\
\text { МВИ, Вт }\end{array}$} & \multicolumn{2}{|c|}{ Продолжительность, сек } & \multirow{2}{*}{ КМГ, \% } & \multirow{2}{*}{$\begin{array}{c}\text { Растворимость } \\
\text { в воде, } \%\end{array}$} & \multicolumn{3}{|c|}{ К-карбоксиметилцеллюлоза } \\
\hline & I & II & & & Выход, \% & КМГ, \% & СП \\
\hline 210 & 20 & 30 & $18,3 \pm 0,3$ & $11 \pm 3$ & $55,9 \pm 0,6$ & $15,1 \pm 0,9$ & 1250 \\
\hline 350 & 20 & 30 & $21,2 \pm 0,4$ & $10 \pm 1$ & $52,0 \pm 0,4$ & $15,5 \pm 0,7$ & 1600 \\
\hline 560 & 20 & 30 & $20,9 \pm 0,2$ & $12 \pm 1$ & $50,1 \pm 0,3$ & $16,4 \pm 0,3$ & 1200 \\
\hline 700 & 20 & 30 & $23,1 \pm 0,4$ & $18 \pm 1$ & $51,8 \pm 0,3$ & $22,3 \pm 0,6$ & 990 \\
\hline 210 & 30 & 30 & $20,2 \pm 0,8$ & $16 \pm 3$ & $57,4 \pm 0,7$ & $10,7 \pm 0,2$ & 1500 \\
\hline 350 & 30 & 30 & $21,3 \pm 0,2$ & $15 \pm 1$ & $55,8 \pm 0,3$ & $11,2 \pm 0,9$ & 1200 \\
\hline 560 & 30 & 30 & $24,2 \pm 0,2$ & $17 \pm 2$ & $55,2 \pm 0,5$ & $13,1 \pm 0,8$ & 1000 \\
\hline 700 & 30 & 30 & $25,6 \pm 0,4$ & $18 \pm 1$ & $48,6 \pm 0,5$ & $19,6 \pm 0,5$ & 1100 \\
\hline
\end{tabular}

Примечания. I - обработка КОН, II - обработка МХУК, СП - степень полимеризации

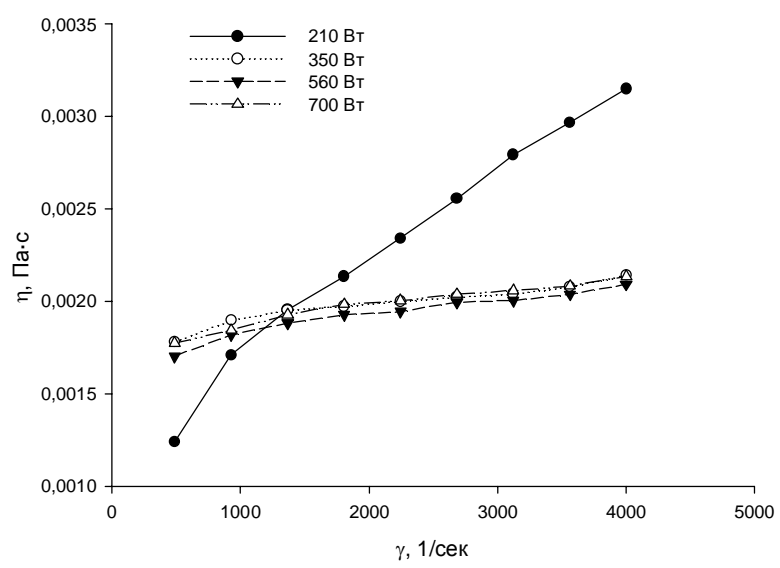

Рис. 1. Изменение вязкости водных растворов калиевой соли карбоксиметилированной древесины сосны, полученной под воздействием МВИ при разной мощности (210-700 Вт)

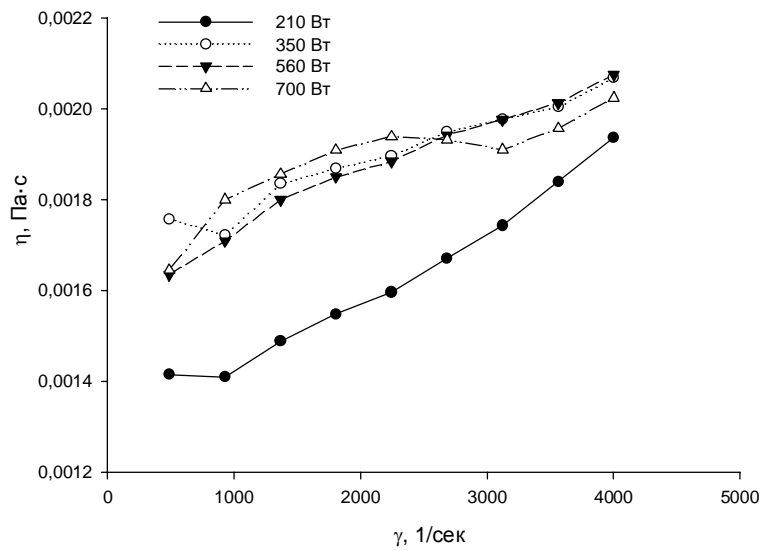

Рис. 2. Изменение вязкости водных растворов калиевой соли карбоксиметилцеллюлозы, выделенной из карбоксиметилированной древесины сосны, полученной под воздействием МВИ при разной мощности (210-700 Вт)

\section{Выводы}

1. Впервые получены калиевые соли карбоксиметилированной древесины сосны под воздействием микроволнового излучения. Получены продукты с содержанием карбоксиметильных групп от 18,3 до $25,6 \%$ и растворимостью в воде $10-18 \%$.

2. Из калиевой соли карбоксиметилированной древесины сосны выделена калиевая соль карбоксиметилцеллюлозы. Показано, что карбоксиметилцеллюлоза содержит от 10,7 до 22,3\% карбоксиметильных групп и имеет степень полимеризации от 990 до 1600, что свидетельствует о слабых деструкционных процессах при карбоксиметилировании древесины сосны под воздействием микроволнового излучения.

3. Изучены реологические свойства водных растворов калиевой соли карбоксиметилированной древесины сосны, полученной в различных условиях микроволнового излучения и выделенной из нее калиевой солью карбоксиметилцеллюлозы. Установлено, что характер кривых вязкости зависит от мощности микроволнового излучения при карбоксиметилировании.

\section{Список литературы}

1. Hill C.A.S. Wood Modification: Chemical, Thermal and Other Processes. John Wiley \& Sons Ltd, 2006. 248 p.

2. Базарнова Н.Г., Катраков И.Б., Маркин В.И. Химическое модифицирование древесины // Российский химический журнал. 2004. Т. XLVIII, №3. С. 108-115.

3. Базарнова Н.Г., Маркин В.И., Колосов П.В., Катраков И.Б., Калюта Е.В., Чепрасова М.Ю. Методы получения лигноуглеводных композиций из химически модифицированного растительного сырья // Российский химический журнал. 2011. Т. 55, №1. С. 4-9. 
4. Маркин В.И., Базарнова Н.Г., Галочкин А.И. Изучение влияния предобработки на карбоксиметилирование древесины березы в среде изопропилового спирта // Пластические массы. 1998. №7. С. 31-34.

5. Базарнова Н.Г., Маркин В.И., Галочкин А.И., Токарева И.В. Алкилирование лигноуглеводных материалов с использованием механохимического метода // Химия в интересах устойчивого развития. 1998. №6. С. $223-227$.

6. Маркин В.И. Карбоксиметилирование растительного сырья. Теория и практика. Барнаул, 2010. 167 с.

7. Чепрасова М.Ю., Маркин В.И., Базарнова Н.Г., Коталевский И.В. Карбоксиметилирование древесины под воздействием микроволнового излучения в среде различных растворителей // Химия растительного сырья. 2011. №1. С. 77-80.

8. Оболенская А.В., Ельницкая 3.П., Леонович А.А. Лабораторные работы по химии древесины и целлюлозы. M., 1991. $411 \mathrm{c.}$

9. Базарнова Н.Г. Химия древесины и ее основных компонентов. Барнаул, 2002. 52 с.

10. Калюта Е.В., Базарнова Н.Г., Маркин В.И. Влияние продолжительности обработки надуксусной кислотой карбоксиметилированной древесины на свойства выделяемой карбоксиметилцеллюлозы // Химия растительного сырья. 2006. №2. С. 29-31.

11. Окатова О.В., Лавренко П.Н., Horst Dautzenberg. Гидродинамические свойства и конформационные характеристики молекул низкозамещенной карбоксиметилцеллюлозы в растворе // Высокомолекулярные соединения. Серия А. 2000. Т. 42, №7. С. 1130-1137.

Поступило в редакцию 30 декабря 2012 г.

После переработки 19 июня 2013 г.

Markin V.I.*, Cheprasova M.Iu., Bazarnova N.G., Frolova E.O. PREPARED POTASSIUM SALT OF CARBOXYMETHYL PINE WOOD IN A MICROWAVE

Altai State University, pr. Lenina, 61, Barnaul, 656049 (Russia), e-mail: markin@chem.asu.ru

Microwave radiation to intensify the process of carboxymethylation of pine wood without prior separation of the individual components is proposed to use. Carboxymethylated pine wood in the form of the potassium salt obtained by treating the pine potassium hydroxide and monochloroacetic acid in 2-propanol . Composition and properties of the products were investigated . Carboxymethylcellulose isolated from carboxymethylated pine wood. Increasing the power of microwave radiation (210 to $700 \mathrm{~W})$ and the duration of the first and second stages of the process of carboxymethylation $(20-30 \mathrm{sec})$ increases the content of carboxymethyl groups (18,3-25,6\%). Abnormally low solubility of the potassium salts of carboxymethylated pine wood (10-18\% ) compared to the sodium salt with a comparable content of carboxymethyl groups was detected. Study viscosity of aqueous solutions carboxymethylated pine and carboxymethylcellulose derived from it was performed. It is shown that the samples obtained at microwave power of $210 \mathrm{~W}$ have abnormal flow curves.

Keywords: microwave radiation, carboxymethylation, potassium salt, wood, carboxymethylcellulose, flow curves.

\section{References}

1. Hill C.A.S. Wood Modification: Chemical, Thermal and Other Processes. John Wiley \& Sons Ltd, 2006. 248 p.

2. Bazarnova N.G., Katrakov I.B., Markin V.I. Rossiiskii khimicheskii zhurnal, 2004, vol. XLVIII, no. 3, pp. $108-115$. (in Russ.).

3. Bazarnova N.G., Markin V.I., Kolosov P.V., Katrakov I.B., Kaliuta E.V., Cheprasova M.Iu. Rossiiskii khimicheskii zhurnal, 2011, vol. 55, no. 1, pp. 4-9. (in Russ.).

4. Markin V.I., Bazarnova N.G., Galochkin A.I. Plasticheskie massy, 1998, no. 7, pp. 31-34. (in Russ.).

5. Bazarnova N.G., Markin V.I., Galochkin A.I., Tokareva I.V. Khimiia v interesakh ustoichivogo razvitiia, 1998, no. 6, pp. 223-227. (in Russ.).

6. Markin V.I. Karboksimetilirovanie rastitel'nogo syria. Teoriia i praktika. [Carboxymethylation plant materials. Theory and practice]. Barnaul, 2010, 167 p. (in Russ.).

7. Cheprasova M.Iu., Markin V.I., Bazarnova N.G., Kotalevskii I.V. Khimiia rastitel'nogo syr'ia, 2011, no. 1, pp. 77-80. (in Russ.).

8. Obolenskaia A.V., El'nitskaia Z.P., Leonovich A.A. Laboratornye raboty po khimii drevesiny $i$ tselliulozy. [Laboratory work on the chemistry of wood and cellulose.]. Moscow, 1991, 411 p. (in Russ.).

9. Bazarnova N.G. Khimiia drevesiny $i$ ee osnovnykh komponentov. [Wood Chemistry and its main components]. Barnaul, 2002, 52 p. (in Russ.).

10. Kaliuta E.V., Bazarnova N.G., Markin V.I. Khimiia rastitel'nogo syr'ia, 2006, no. 2, pp. 29-31. (in Russ.).

11. Okatova O.V., Lavrenko P.N., Horst Dautzenberg. Vysokomolekuliarnye soedineniia. Seriia A, 2000, vol. 42, no. 7, pp. 1130-1137. (in Russ.).

Received December 30, 2012

Revised June 19, 2013

\footnotetext{
"Corresponding author.
} 